\title{
Axiological competences: The role of teacher training programme in strengthens it.
}

\author{
POOJA CHATURVEDI \\ (Lecturer, Advance institute of management, Ghaziabad)
}

\begin{abstract}
This paper addresses the impact of Axiological competences in teachers' trainingprogramme andits response to the demand for value development in the school \& society. Theauthor advocates the need for the preparationof a teacher as an agent for social change and future maker, to equip him to deliver thequality of values as per the situation and explore the process by which childrendevelop values essential for living in the society. In this educational context, the research agenda must be re-opened for teachers to regulate their views on teaching and use a more value-laden approach to teaching and learning.

Teachers need to be trained to create situations and be imaginative to reflect on that situation by makingstudents aware of values and highlighting its need.Pupil-teacher should enjoytraining for the 'pleasure of recognition' and 'joy of understanding', and inthis process they become aware of cultural ethos and values, which areconveyed through messages in an implicit manner.

Thispaper emphasises that teaching is a localised phenomenon with aninternational outlook. Value education implies that the child is a collaborator in the learning process and the teacher is a facilitator. The paper also presents some of the features in Axiological competences carried out at in teacher training programmed. The researcher is of the opinion that Axiology based teacher education may be imparted throughdirect as well as indirect methods. This paper highlights that value development in teacher training programmedhas to go through many stages and activities. It identifies specific principles and suggests some activities to developthem through daily school routines.
\end{abstract}

Key Words: Axiology, competences, Teacher Training, Values, Principles.

\section{Introduction}

Indian culture and heritage is inherent from its rich tradition, diverse migration specific rituals,distinguish standards and behaviour. The uniqueness of Indian culture and literature lies in its strong social system and values. The ancient education system infused a sense of responsibilities, social, intellectual and cultural values, perfect social life, and ideal citizenship, and ultimate religion, aptitude to think and act for the benefit of the entire world. By means of education efforts were being made of inculcate Satyam, Shivam and Sundaram. Our ways of thinking was base on Epistemology, Ontology and Axiology. Our beliefs, perception, way of thoughts, imparting knowledge mostly focused on these classification of values which are-

Dharma (Virtues)- a Moral value, Artha (Wealth)-An E economic Value., Karma (Pleasure) - A Psychological Value., Moksha (Self-realisation) - A Spiritual Value.

Indians Are now moving away from the concept of values and ethics. Due to deterioration and deviation from value system, we need axiological competences in human beings specially teachers. A teacher is an organizer of ideas and themes. At home the child's ideals are his parents and in school he forms his ideals around his teacher. Therefore, we need rationally, socially and sensitively good teachers and this further depends on the quality of education provided to the pupil-teacher in the Educational Training Institutions. Inside of old thoughts 'teacher in born' now training institute focus on 'teacher is made 'through develop specific traits in teacher trainees. To conclude the teaching system helps a aspirant- teacher to become a skilled teacher with strong value system and mental strength and develops qualities that gift our nation with teacher that can be considered at par with the by birth teachers.

According to American Commission on Teacher Education1974. "The quality of a nation depends upon the quality of its citizens and the quality of its citizens depends upon the quality of their education. Further, the quality of their education depends more than any other single factors, upon quality of their teachers." No people can rise above the level of teachers. Teachers can either make or mar the society. In teacher they have the ability of understanding the children's emotions and their causes, the capability of effectively regulating these emotions in oneself and in others and most importantly being able to use the emotions a source of information for problem solving, being creative and dealing with social situations. Initially India faces the shortages of getting trained and qualified teachers, particularly in the remote and far flung regions in country. It was said that some individuals were teacher by birth. But the present scenario is such that it cannot wait for those individuals. There is an urgent need of good teaching individuals. 
We cannot risk future of our nation in the hands of under qualifier or untrained teacher appointed in schools. Their requirements have led to the development of teaching system which brings out and sharpens the quality in individual. The system increases situation handling capability and develops adoptability to all kinds of environment. Axiological based teacher education provides an opportunity to reflect upon the critical, social, economic, cultural, moral and spiritual issues facing humanity but it is deteriorated in terms of quality and relevance.

\section{Axiological Competence}

Axiology derived from Greek word-axios (worth or value) and logos (study or theory) means theory of values. Axiology is the science of human values, enables us to identify the internal valuing systems that influence our perceptions, decisions and actions-to clearly understand 'why' we do what we do! Axiology are traits or qualities that are considered worthwhile, they represent an individual's highest priorities and deeply held driving forces. Axiology has 2 main branches, Ethics and Aesthetics.

Ethics is the study of moral values and conduct. While Aesthetics deals with theoretical aspects of art.An axiological competence isdevelopment in the sense that it is education for 'becoming '. It is concerned with the development of the total personality of the individual-intellectual, social, emotional, aesthetic, moral and spiritual. It involves developing sensitivity to the good, the right and the beautiful, ability to choose the right values in accordance with the highest ideals of life and internalising and realising them in thought and action.Finally axiological competences are the horizon of the manifestation of human creativity.

Conventionally it has been considered that axiological competence should be done on the basis of strong personal commitment, but we supported the proposal of a conscious training on value to promote intercultural understanding. In other words, to 'value educate' is to develop rational critical thinking, to educate the emotions, to cultivate the imagination, to strengthen will and to train character of the learner. The purpose is to kindle the moral and aesthetic sensibilities of learners, to raise their level of value consciousness, to stimulate them to think freely and critically, to develop the ability to judge actions and events rationally, and to choose and act courageously and with conviction for the sake of the larger social good. Accordingly, the teacher has to be trained to function as anagent who stimulates, provokes, informs and sensitises the learners with reference to value situations in life.

\section{Teacher Training Programme}

Our education system conduct many Pre-service and In-service teacher training programme in India such as-N.T.T, B.T.C, Special B.T.C, J.B.T, B.Ed, Special B.Ed, M.Ed, D.Ed and refresher courses. The different bodies at state and national level like-ISDR, NCERT, DIET, DSERT, and NCTE must intervene for the progress and development of a good standard of education. That has the responsibility of producing the efficient and competent teachers.

"A teacher training programme is assuredly sacred consign where a divine task is being put in to actionthe shaping and moulding of the fortunes of many generations of the country."

The institutional processes in the training institution should help teachers acquire some

Capabilities by providing concrete situations and opportunities and actively involve them in appropriate learning experiences. The teachers' training experience in its totality should lead to the motivation of teachers towards the attainment of these ideals. High quality of educational system is the compulsory demand of any nation's development. For the fulfillment these particular purpose educational institutes provide high quality training for students. Thus axiological development of this teacher training system has now become mandatory. These are sources of teachers which are trained professionals who are friendly, cheerful, good natured, patient, companionable, not irritating and not aloof. They are fair in grading and marking and impartial in every situation. The teacher plays an important role in moulding the personality of students. It is teachers who by his action, his thought, work, and ideas leave an everlasting impact on the mind of students. A teacher who is imbibed with good values of life is appreciated and become a role model forstudents. If a teacher has keen sense of values and has faith in higher purpose of life, he can guide the whole generation through his versatile personality. The teachers may motivate, communicate illustrate activate and inculcate the values among the students by curricular and co-curricular activities. The teacher should develop leadership skills and responsibilities promote positive leisure activities.

\section{Guiding Principles For Teacher Training Programme}

$>$ Principle of learner's centered.

$>$ Principle of Intellectual, cultural and social ethics.

$>$ Development of child's entire personality.

$>$ Principle of work- commitment.

$>$ Principle of comprehensive curriculum. 
$>$ Principle regularity and Accountability.

$>$ Transformation into activity schools.

$>$ Principle Of human relationship.

$>$ Principle of dynamic personality.

$>$ Axiological and professional competence.

$>$ Principle of Centre of community service.

$>$ Opportunities for Self-Discipline.

$>$ Trainingin the art of living together.

$>$ Sense of Dedication, Devotion and Creation.

$>$ Principle of democratic out look.

$>$ Principle of excellence with sincerity.

$>$ Principle of change, rest and recreation.

$>$ Principle of curiosity, creativity\& logical thinking.

\section{Impact Of Axiological Competences In Teacher Training Programme}

Axiology, by projecting a system of values proposes educational aims, under the form of axiological objectives and ideals. Axiological competence determinesthe general /universal and specific values in the society that form a Balanced personality of human beings. The performance of values requires knowledge and experience, which means the involvement of three interrelated plans-cognitive, affective and co native. Impartial personality of Pupil-Teacher preserves and transmits values that guarantee the cultural identity of the human community it's refer to maintain spiritual, intellectual and social norms of the humanity. Social ethics and norms devotee always construct a new moral and ideal example. This represents the aspirant- teacher as a Role model in a society. At last hopeful teacher becomes an effective teacher. The teacher can thus be seen as one of the most important figures for pre-adult new comers to a new society. The role of the teachers certainly implies the power to influence students, and since values are inherent in teaching, it seems unlikely that students will be able to avoid the influence of teacher's values completely. That's why axiological competences constantly strengthening the teacher training programmeand prepare efficient teachers. This is a continuous, interconnected and inter-related process, diagrammatically presented as below-

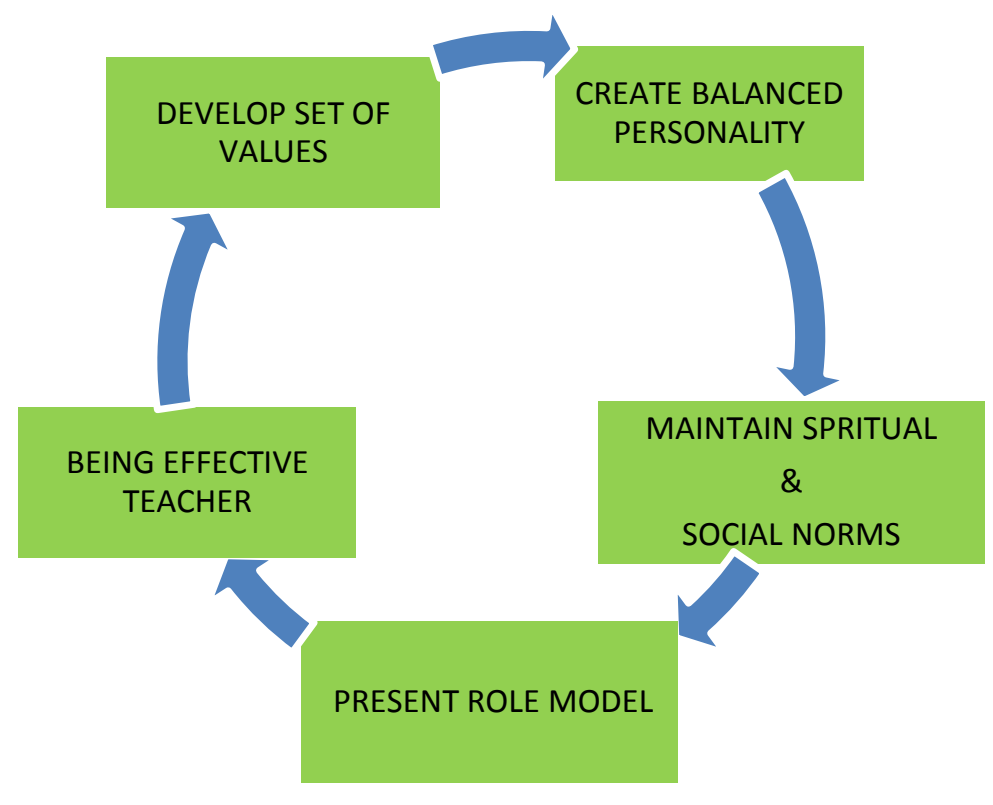

Diagrammatically presentation of impact of Axiological competence.

We systematize debates, quizzes, interviews, dramatization, wallwriting, elocution etc. on the life style of great philosopher, so that deep understanding towards values can be developed among the students. The products of these programmes should necessarily have the following importance in the context of value -development.

\section{Magnitude Of Axiological Competence In Present Context}

The following can be enumerated as the significance of axiological competence, which strengthens the teacher-training programme:

- To inculcate moral and spiritual values for human caring. 
- To achieve the educational and social objectives.

- To arouse scientific attitude and democratic out look.

- To develop high degrees of intellectual and moral maturity.

- To lead life independently with responsibility, accountability and caring.

- To develop physical, intellectual and aesthetic aspects of personality.

- To mould the balanced personality for social motivation.

- To train student-teachers to become responsible citizens.

- To improve the axiological and professional competence.

- To motivate to improve the socio-economic condition.

- To develop cultural, social and vocational competences.

- To learn adjustment with changing condition.

- To build up accurate modification in behaviour.

- To develop good habits supported by feeling and rational thinking.

- To create awareness of the physical, social, moral \& cultural environment.

- To promote national integration \& international understanding.

- To enable a healthy attitude to dignity of labour and hard work.

- To develop the positive and healthy attitude towards life.

- To develop self-confidence to innovative \& face unfamiliar situations.

- To dedicate the uphold integrity, honours and foster development of country.

- To avoid deviation from the Goal and society norms.

- To evaluate the teacher' knowledge \& performance.

- To organizethe effective teaching-learning process.

- To develop the ability to judge action.

- To raise their level of value consciousness.

- To stimulate person to think freely and critically.

- To promote moral and aesthetic sensibilities of learners.

- To manifestation of human creativity.

- To make optimum \&desirable utilization of resources.

- To develop work commitment and long term vision.

- To bring quality and meaning to life.

- To give a persons his identity and character.

- To provide guide lines.

- To realizes us to we the best creature of nature.

- To create harmony in all aspects of educational philosophy.

- To promote positive leisure activities.

- To establish close rapport with the living beings.

- To participate in developmental activities.

- To nurture spiritual ideals \& religious tolerance.

\section{Conclusion}

As above discussion we conclude that axiological competence is very important for us. The ultimate aim of the teacher training programme must be value-oriented to develop the physical, intellectual and emotional facetsof the child's personality.Itenhances Axiological and professional competence among teachers. Value acquisition goes on constantly in the school and training institute through various activities like organizing assembly, educational excursion, historical visit, art and painting competition, seminar and workshop, celebration of national \& international days, festivity of eminent personality's birthdays, co-curricular activities, and yoga meditation, fasting, study of sacred\& spiritual books, services to humanity, alms to poor and deserves, plantation ,poster making contest, essay writing etc. that's why students gaining a greater capacity for selfreflection and self-appraisal.

The observations of the training institute indicated the "profound potential of Axiological competence \& value education to transform the learning environment, ethos, coherence, sense of self fulfillment and inclusiveness of a institute and, in so doing, to stimulate student social development by strengthening relationships between students, and students and teachers. Researcher advocated that high degree of intellectual, moral and axiological aptitude influence the training programme and competent training programme build up values among human beings. So in future the efficient teacher should try to inculcate moral \& spiritual values among the students which create self-actualisation. 


\section{References:}

[1]. Ahmad,A.(1999) Management of human values: An overview. Journal of Human Values.

[2]. Anand, S.P. (1980). Teacher's values and job satisfaction, Indian Education Review

[3]. Bharadwaj.Tilak Raj,(2001)Education of human values, Mittal publications New Delhi.

[4]. Bhushan, A, and Ahuja, M. (1980). Value System and value preference of Indian youthbelonging to different scio-metric levels", journal of Institute of Education Research

[5]. Dagar, B.S. \&Dhull, A case for Value- Oriented Education. University News.

[6]. Gupta, B.M.(1997) Role of Induction Programme in Teaching Effectiveness. Journal of Indian Education.

[7]. Jasta, Hari Ram (1990). Spiritual Values and Education, Published by PrabhatParkashan, Delhi.

[8]. Joshi,Kiret.(1999) Fundamental duties and human values. The Indian journal for teacher education.

[9]. Krishna, Prasad. (2001)Education in values-strategies and challenges for value education. National institute of technology ,Calicut.

[10]. Ksheerasagar, Surekha. (2010) Value - oriented Education ,The Need of the Hour, .Edutracks.Neelkamal publications pvt.ltd.

[11]. Matveer,V. Alexei. (2008)The Value of intercultural competences for performance of Multicultural teams.The University of New York.

[12]. Ojeda, Juan Ramon Guijarro(2006)The Role of Axiological Competence in EFL Teacher-Training: Opening Doors to OthernessFriendly Pedagogies, twelfth international conference on learning, Granada.

[13]. Rushdy, Sherif. (2005)Value-based teachers' training at new era development institute. Research paper N.C.E.R.T. New Delhi

[14]. Seshadri, C. (2005). "An approach to value orientation of teachers' education" Journal of Value Education, NCERT, January \&July 2005 issue.

[15]. Singh Amardeep, (2011), Evaluating the Impacts of Value Education: Some Case Studies

[16]. International Journal of Educational Planning \& Administration, Research India Publications

[17]. Venkataiah N., (2004) Value Education, Published by A.P.H. publishing corporation 